\title{
The effect of the channel height on the critical heat flux in a shear-driven liquid film
}

\author{
D. Zaitsev"1,a, O. Kabov ${ }^{1}$ \\ ${ }^{1}$ Institute of Thermophysics SB RAS, 1, Lavrentiev Ave, 630090, Novosibirsk, Russia
}

\begin{abstract}
The fast development in semiconductor technology has led to increasingly higher chip power dissipation and greater non-uniformity of the heat dissipation with the result of localized hot spots, often exceeding $1 \mathrm{~kW} / \mathrm{cm}^{2}$ in heat flux. As was shown in previous works of the authors, thin and very thin liquid films driven by a forced gas/vapor flow (stratified or annular flows), i.e. shear-driven liquid films in a narrow channel are promising candidate for an innovative cooling technique optimizing the tradeoffs between performance and cost. The goal of the present work is to study the effect of the channel height on the critical heat flux (CHF) in a locally heated liquid film driven by the shear stress of gas in a channel.
\end{abstract}

\section{Introduction}

One of the most important problems of thermal physics today is cooling of microelectronic equipment. Currently, the production of processors changes over from the $14 \mathrm{~nm}$ manufacturing process technology to the $7 \mathrm{~nm}$ technology. New IBM processors use $7 \mathrm{~nm}$ transistors. This has been made possible through the use of a silicon-germanium alloy in the transistor design instead of pure silicon, the traditional material for the manufacture of microchips. A normal-size processor can accommodate more than 20 billion transistors having a size of $7 \mathrm{~nm}$. In addition to reducing the size of the microprocessor unit, the use of the silicon-germanium alloy has improved the switching speed of transistors and lowered the power consumption. The average heat flux density on the chips of commercially available computers and other electronic devices is up to $200-300 \mathrm{~W} / \mathrm{cm}^{2}$. In local areas of $100 \mu \mathrm{m}^{2}$ to a few cubic millimeter, the heat flux density reaches values of $1 \mathrm{~kW} / \mathrm{cm}^{2}$ or more (IBM). Devices of the next generation may have higher heat fluxes and pulsed loads [1], whose combination requires a new thermal management level. Two-phase flows are of particular interest for use in cooling systems because of high heat-transfer coefficients. The latent heat of evaporation in two-phase flow usually provides much greater cooling capacity than single-phase flow, allowing the use of lower mass flow rates.

The use of two-phase systems is not limited to microelectronics. Recently, there has been an increased interest in transport processes in mini- and microsystems, caused by the rapid development of medicine, as well as the miniaturization of devices in various fields of technology, for example, in the automotive, aerospace, and transportation industries. Thus, there has been a breakthrough development of heat exchange systems with micro- and nanodimensions, and these systems are much more energy efficient than macrochannels with channel dimensions of 3-100 mm.

\footnotetext{
${ }^{\text {a }}$ Corresponding author : zaitsev@itp.nsc.ru
} 
As shown in [2], thin and very thin liquid films driven by a forced gas/vapor flow (stratified or annular flows), i.e. shear-driven liquid films in a narrow channel are promising candidate for an innovative cooling technique optimizing the tradeoffs between performance and cost. Works [3-7] are devoted to experimental and analytical study of hydrodynamics, heat and mass transfer and crisis phenomena during joint motion of intensively evaporating liquid film and gas flow in the horizontal channel with a local heater (simulating an electronic device). The goal of the present work is to experimentally study the effect of the channel height on the critical heat flux in such a cooling system in the range of the channel heights from 0.17 to $2.00 \mathrm{~mm}$.

\section{Experimental setup}

Schematic of the test section is presented in figure 1 . The main part of the test section is a $4 \mathrm{~mm}$ thick stainless steel plate with a flush-mounted copper rod. At the working surface the rod has a $1 \times 1 \mathrm{~cm}$ square head emulating surface of a computer chip. The rod is heated by a heating spiral coiled around its lower part (not shown in figure 1). Such construction of the heater provides the condition at the heater surface $\mathrm{T}=$ const (which is confirmed by thermocouples measurements). The test section is covered with a transparent cover made of optical glass so that a flat channel is formed (the cover is not shown in figure 1). The channel height, $\mathrm{H}$, varies from 170 to $2000 \mu \mathrm{m}$. Gas, pumped by a compressor, flows through the channel and passes to the atmosphere at the end of the test section. The liquid is supplied from a thermostat, gets into the channel through a liquid nozzle and flows under the friction of the gas along the stainless steel plate as a film. The liquid is accumulating at the bottom part of the test section and is returned into the thermostat. Several thermocouples are embedded in the stainless steel plate and in the copper rod, allowing determination of the working surface temperature. The temperature of the heater surface is calculated taking into account the depth at which the thermocouples are embedded $(2 \mathrm{~mm})$. All the thermocouples are individually calibrated to an accuracy of $0.1^{\circ} \mathrm{C}$. The test section is oriented horizontally.
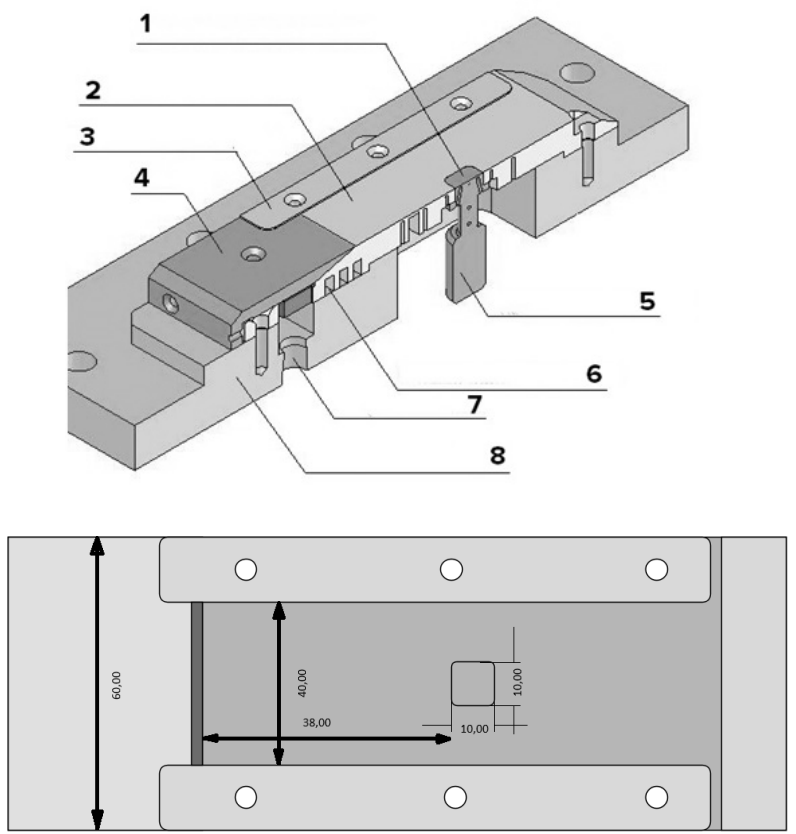

Figure 1. Design of test section: 1- source of the local heating; 2- stainless steel plate; 3- channel height control; 4- knife; 5- copper rod; 6- thermostabilizer; 7- liquid inlet; 8- textollite substrate. 
The working surface of the test section was mechanically polished. The morphology of the surface was analyzed using scanning electron microscope (JEOL JSM6700F) and atomic force microscope (Solver Pro NT MDT). The root mean square (RMS) surface roughness, measured on a $22 \mu \mathrm{m}^{2}$ area of the heater surface, was found to be $790 \mathrm{~nm}$.

Ultra-pure water (Merck Millipore) with initial temperature of $24^{\circ} \mathrm{C}$ is used as the working liquid. Air with temperature of $24-27^{\circ} \mathrm{C}$ and relative humidity of $15-30 \%$ is used as the working gas. The experiments are carried out under stationary conditions. Superficial gas velocity (volumetric gas flow rate divided by cross-sectional area of the channel) $\mathrm{U}_{\mathrm{Sg}}$ varies from 2.5 to $50 \mathrm{~m} / \mathrm{s}$. Liquid Reynolds number $\operatorname{Re}_{1}$ varies from 18 to 70 .

The heat flux $q$ is determined by the electrical power dissipated on the heating spiral. Thermal conductivity of copper is $400 \mathrm{~W} / \mathrm{mK}$ which is almost 30 times higher than that of stainless steel (15 $\mathrm{W} / \mathrm{mK}$ ). This provides moderate heat spreading from the heater to the stainless steel plate: about $15 \%$ at $\mathrm{q}>200 \mathrm{~W} / \mathrm{cm}^{2}$, about $20 \%$ at $\mathrm{q}=100 \mathrm{~W} / \mathrm{cm}^{2}$ and up to $30 \%$ for smaller heat fluxes (according to estimation using measurements of thermocouples embedded into the stainless steel plate). Heat spreading into the atmosphere has been calculated as the ratio of the heat flux between two thermocouples embedded into the copper rod (estimated by measurements of thermocouples) and the total heat flux determined by the electrical power. In order to minimize heat spreading from the heating spiral into the atmosphere, the heating spiral is wrapped with a layer of heat insulation material (mineral wool). Heat loses into the atmosphere don't exceed $10 \%$ at $\mathrm{q}>200 \mathrm{~W} / \mathrm{cm}^{2}$. Thus, the heat loses into the atmosphere and heat spreading into the steel plate in total don't exceed $25 \%$ at heat fluxes higher than $200 \mathrm{~W} / \mathrm{cm}^{2}$. All data below are presented without taking into account the heat losses and heat spreading.

\section{Experimental results}

Figures 2 and 3 show the flow in the channel prior occurrence of the heat transfer crisis for the channel height $\mathrm{H}=250$ and $2000 \mu \mathrm{m}$, respectively. For $\mathrm{H}=250 \mu \mathrm{m}$ the heater is covered with nonstable, evaporating liquid film at both superficial gas velocities $U_{\mathrm{Sg}}=5$ and $30 \mathrm{~m} / \mathrm{s}\left(\right.$ at $U_{\mathrm{Sg}}=5 \mathrm{~m} / \mathrm{s}$ the liquid is touching the glass cover). However, for $\mathrm{H}=2000 \mu \mathrm{m}$ the heater is covered with nonstable liquid film only at relatively high gas velocity $\left(U_{\mathrm{Sg}}=33 \mathrm{~m} / \mathrm{s}\right)$, while for smaller gas velocity $\left(\mathrm{U}_{\mathrm{Sg}}=2.5\right.$ $\mathrm{m} / \mathrm{s}$ ) the first dry patch propagates all over the heater (the liquid is not touching the glass cover in this case), causing dryout and thus the occurrence of the heat transfer crisis.

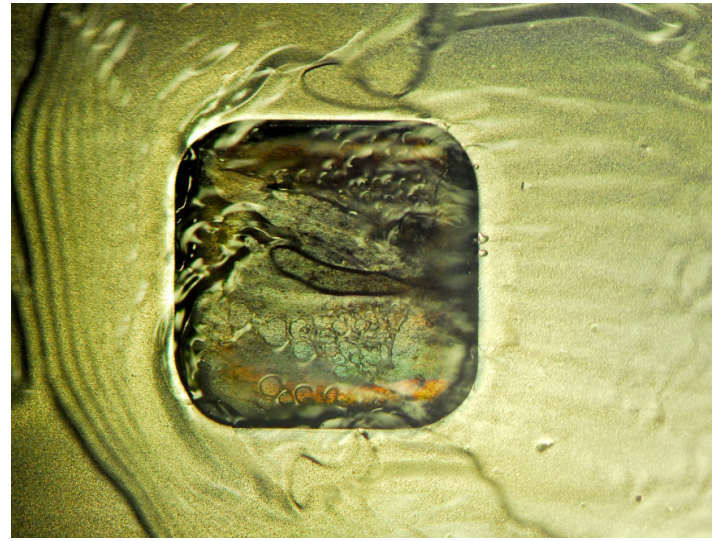

a) $\mathrm{Usg}=5 \mathrm{~m} / \mathrm{s}, q=210 \mathrm{~W} / \mathrm{cm}^{2}$

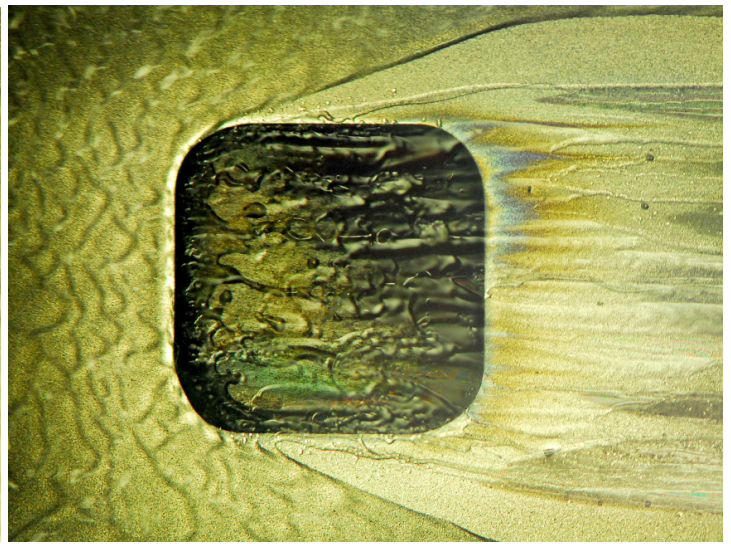

b) $\mathrm{Usg}=30 \mathrm{~m} / \mathrm{s}, q=250 \mathrm{~W} / \mathrm{cm}^{2}$

Figure 2. Photograph of the flow prior to the critical heat flux for $H=250 \mu \mathrm{m}, \mathrm{Re}=18$. The flow directed from left to right. 


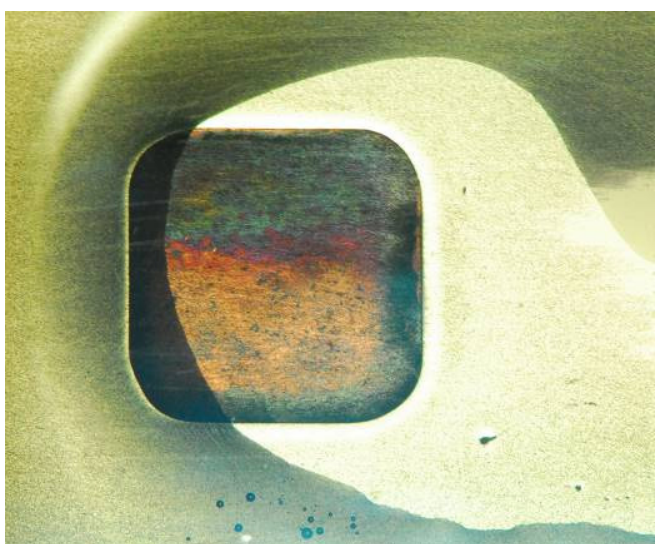

a) $\mathrm{Usg}_{\mathrm{sg}}=2.5 \mathrm{~m} / \mathrm{s}, q=40 \mathrm{~W} / \mathrm{cm}^{2}$

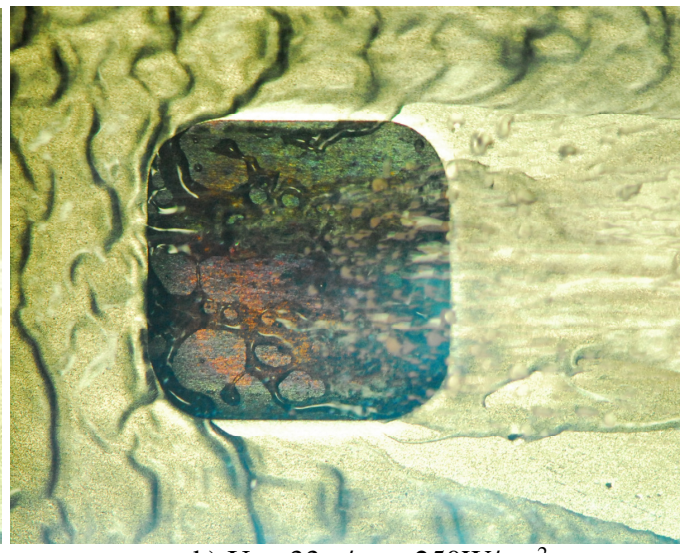

b) $\mathrm{U}_{\mathrm{sg}}=33 \mathrm{~m} / \mathrm{s}, q=250 \mathrm{~W} / \mathrm{cm}^{2}$

Figure 3. Photograph of the flow prior to the critical heat flux for $H=2000 \mu \mathrm{m}, \mathrm{Re}_{\mathrm{l}}=18$. The flow directed from left to right.

Figure 4 shows the effect of the channel height on the critical heat flux for different superficial gas velocities. It is seen that for $\mathrm{H}=170-250 \mu \mathrm{m}$ the critical heat flux is weakly dependent on the superficial gas velocity, while for $\mathrm{H}=1-2 \mathrm{~mm}$ the critical heat flux strongly decreases with decrease of the superficial gas velocity. For relatively small superficial gas velocities the critical heat flux sharply decreases with the channel height, while for relatively high superficial gas velocities the critical heat flux slightly increases with the channel height.

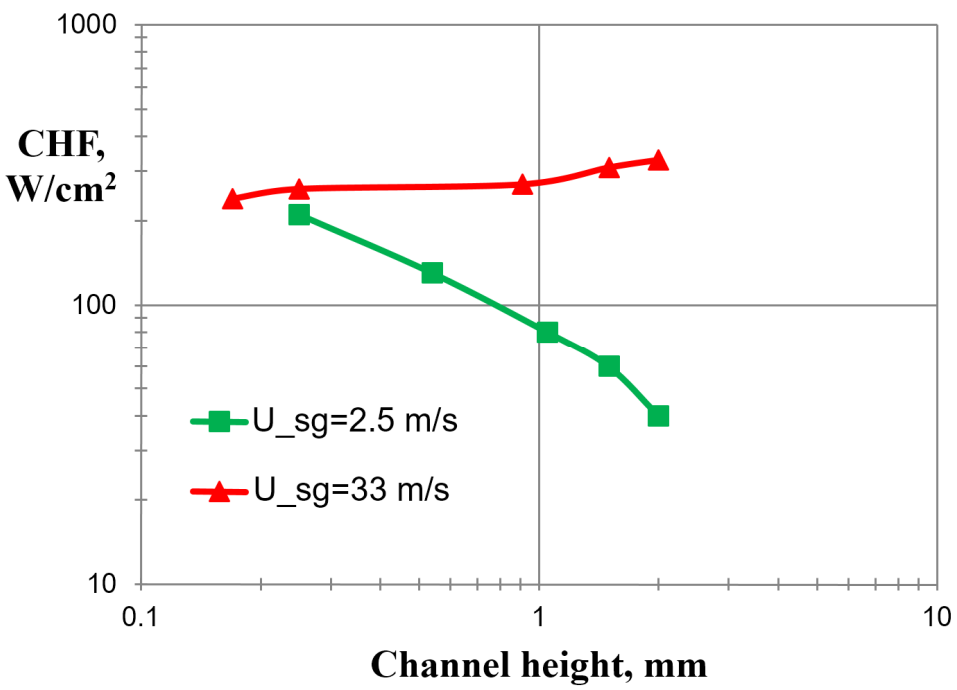

Figure 4. Critical heat flux vs. channel height for different superficial gas velocities, $R_{\mathrm{l}}=18$.

\section{Conclusions}

For a locally heated liquid film shear-driven in a microchannel with the height of $\mathrm{H}=170-250 \mathrm{~mm}$ the critical heat flux was found to be weakly dependent on the superficial gas velocity, while for the liquid 
film shear-driven in a minichannel with the height of $\mathrm{H}=1-2 \mathrm{~mm}$ the critical heat flux was found to strongly decrease with the decrease of the superficial gas velocity. Thus we conclude that cooling systems with shear-driven liquid films in microchannels are more reliable than those with shear-driven liquid films in minichannels.

This work was supported by the Ministry of Education and Science of Russia (Agreement No 14.604.21.0053, project identifier RFMEFI60414X0053).

\section{References}

1. Bar-Cohen A, Wang P. ASME. J. Heat Transfer, 134(5), 051017 (2012).

2. Kabov O.A., Lyulin Yu.V., Marchuk I.V. and Zaitsev D.V. International Journal of Heat and Fluid Flow 28 103-112 (2007).

3. Zaitsev D.V., Rodionov D.A. and Kabov O.A. Technical Physics Letters 35 (7) 680-682 (2009).

4. Kabov O.A. and Zaitsev D.V. Multiphase Science and Technology 21 (3) 249-266 (2009).

5. Kabova Y.O. Technical Physics Letters, 39 (10) 902-905 (2013).

6. Kabova Y., Kabov O., Gambaryan-Roisman T., Stephan P., Kuznetsov V.V. Int. Journal of Heat and Mass Transfer, 68, 527-541 (2014)

7. Gatapova E.Ya., Graur I.A., Sharipov F., Kabov O.A. Int. Journal of Heat and Mass Transfer 83 235-243 (2015). 